the gas organisms in this direction, one can only conjecture. It was impossible at the time of the operation to obtain a specimen from the aqueous, as the cornea gave way as soon as the globe was touched.

The three drawings of the eye have been done for me by Sergt. Maxwell, R.A.M.C., from rough sketches made at the time, and I should like to take this opportunity of thanking him for the excellent way in which he has carried out the work. They give a very good idea of the appearance of the cornea at different stages, and also show the entrance wound at the inner canthus, and the masses of chemosed conjunctiva filling up the gap in the lower lid. In the first drawing the large area of opaque cornea is clearly seen, with the ulcer down and in, and the rows of bubbles slightly ahead of the advancing infiltration. The second drawing gives the appearance half an hour later, when the bubbles had run together, and the infiltration had spread further towards the upper edge of the cornea; whilst the last drawing shows the cornea completely opaque, with the large bubble at the upper edge, which burst as the sketch was being made.

\title{
A NEW TEST TYPE FOR THE DETECTION OF MALINGERERS IN ARMY WORK
}

\author{
BY \\ Alan W. Sichel, B.A., M.B., Ch.B. (Edin.) \\ Captain, R.A.M.C.
}

IN examining the visual acuity of men in the Army the ophthalmic surgeon has to contend with malingering, and in many cases the detection of a malingerer is a matter of some difficulty.

Out of 1,956 cases where the visual acuity was examined at No. - Ophthalmic Centre during a period of twelve months, 101 cases of malingering were recorded, representing about 5 per cent. of all eye cases seen.

By malingering in this connection is meant the refusal of men to admit having as high a visual acuity as they really possess, whether they be emmetropic or have an error of refraction small or moderate in amount.

Malingering in the Army differs from that met with by the oculist in civil practice in this respect; in the latter case the malingerer usually maintains that he is blind in one or both eyes, or at any rate that he has no useful vision in one or both eyes in order to claim compensation for an injury alleged to have been caused by his work. In Army work, on the other hand, the type of 
malingerer met with is one who pretends that his vision, while fairly good, is below a certain standard. This is due to the fact that in classifying men as to their fitness for the various categories as regards visual acuity, certain standards are laid down, e.g., to be fit for category A a man must see at least $6 / 24$ with either eye without glasses and at least $6 / 12$ with the right eye with glasses. In order to be rejected for category $\mathrm{A}$, a man must maintain that he cannot see more than $6 / 36$ with either eye without glasses, or that he cannot see more than $6 / 18$ with the right eye with glasses.

Familiarity with the medical inspection room and the usual test type therein displayed, has enabled men to become acquainted with the card of letters. They know that the large letter $(6 / 60)$ at the top indicates a low standard of vision and that the lowest line (6/6) means a high standard, the intermediate lines from above downwards representing increasingly higher standards. It may even be possible that some men get to know that the fifth line from the top (6/12) is the minimum standard required with glasses for category A.

Accordingly, it is found in examining the visual acuity that in many cases the larger lines are read with comparative ease, but nothing can induce the man to read more than $6 / 18$, even though he be emmetropic, or, having an error of refraction, when this is corrected by glasses. In such cases, when the fundus and media are healthy and the eye is emmetropic or possesses an error of no great amount which is capable of correction, the examiner can only infer that the man ought to see more, and it is obviously a difficult matter to certify the vision to be up to standard when the man declares he cannot see as much as he is expected to. In order to detect cases of this kind, the writer has devised a test card which is intended to prevent the malingerer from judging the standard by the size of the type. The card consists of successive rows of letters constructed upon the usual principles, as in Snellen's test type, but the size of the individual letters varies in each row ; thus, the top row consists of five letters which should be read at 9, 6, 12, 9, and 18 metres respectively, the second row of letters which should be read at $18,12,6,9$, and 24 metres, the third row of letters which should be read at 12, 18, 36, and 9 metres, and the bottom row of letters to be read at $24,6,12,9$, and 18 metres. The distance at which each letter should be read is indicated in small type above the letter. There is no letter of a size which should be read at 60 metres on the card, the largest being one read at 36 metres. In addition to the arrangement of the letters as described, the card employed is smaller in size than the ordinary test card, and this causes the letter to appear relatively larger. There are also four rows of type as compared with seven on the ordinary card.

On being confronted with a card of this kind, the man under examination regards the letter (36), being the largest seen, as equal 
in size to the top letter (60) on the ordinary card. Starting on this erroneous assumption he is tempted to read letters throughout the successive rows one size smaller than he would otherwise have done. It is a matter of some difficulty, even for one accustomed to the ordinary test type, to tell at a glance whether an isolated letter is of a size to be read at 12 or 18 metres, or at 9 or 12 metres; therefore to a man not conversant with such types it is exceedingly difficult.

When the malingerer is asked to read the letters he can see, knowing that it would be foolish for him to say he cannot see even the big letters, he commences to read what he judges to be letters of an intermediate size. If he reads all the letters except those intended to be read at 6 and 9 metres, it is at once known that he can read 6/12 with the eye under examination and this is all that is required, the minimum standard for category A being 6/12 with glasses in the right eye.

What actually happens is, that the malingerer is absolutely bewildered by an arrangement of letters he has not seen before, and in his confusion he blunders into reading smaller letters than he would have done had he proceded from larger to smaller type.

It is important in using the new card that all ordinary test types should be hidden from view, or else the man is afforded an opportunity of comparing the sizes of the various letters with the type arranged in the manner to which he is accustomed.

It is not maintained that every malingerer can be caught in this way, as there is no known method of compelling a man who refuses to read any but the largest letter to admit he can read more, nor is the new card intended to take the place of any of the well known methods for detecting malingerers when these are called for; but after a sufficient trial it has been shown that the large majority of malingerers of this special kind can be detected.

In order to prove the efficiency of the new type, the following routine has been followed. The visual acuity was first recorded as shown by a test card of the ordinary kind. Objective examination in the dark room was then carried out and the refraction noted. The trial frame having been placed in position, the vision of each eye was tested with a plane glass, using the ordinary card. In a few cases the malingerer would read another line or two with the mere addition of a plane glass, but more often than not he still maintained that he could read only what he declared at first. The new test card was then exposed, all ordinary cards being out of sight. In the cases recorded the men were actually shown to have a higher visual acuity by the mere change of cards. The reverse method, i.e., testing first with the new card followed by an ordinary card, revealed the same difference.

In routine work the vision is recorded at the outset by means of the new card, in order that no opportunity may be afforded for 
comparing the size of the type, i.e., judging the standard. In this way the actual visual acuity, or the nearest approximation to it, is obtained without loss of time, and with the minimum of trouble to the oculist, in all but a few cases of malingering.

The card has also proved of use in examining the vision of neurasthenic individuals who perhaps read as far as 6/12, and then say " the rest are blurred." On changing the old for the new type they may read $6 / 9$ or even $6 / 6$ without hesitation.

\section{COUNCIL OF BRITISH OPHTHALMOLOGISTS}

\section{The Visual Requirements of Motor Drivers}

A Committee appointed by the Council of British Ophthalmologists, to report on the visual requirements desirable for those who are granted licences to drive motor vehicles, is desirous of obtaining particulars as to the experience of motor drivers : $(a)$ who are blind in or have lost one eye; $(b)$ who habitually wear distance glasses.

In order that the Committee may base its report on as large an amount of evidence as possible, it requests the assistance of the readers of the BRITISH JOURNAL OF OPHTHALMOLOGY.

It would be glad to receive answers to the following questions* concerning motor drivers coming under either of the above categories. Such answers should be sent to the Hon. Sec. of the Committee, Mr. Elmore Brewerton, 73, Harley Street, W.

\section{Motor Drivers who are blind in or have lost one eye}

\section{Initials :}

Which eye is lost or blind?

When was the sight lost or eye removed?

What is the condition of the sight in the other eye?

Had you driven a motor car before the loss of the eye, and, if so, for how long?

For how long and in what districts have you driven a motor car since the loss of the eye ?

What kind of motor vehicle have you been driving ?

Have you at any time, since the loss of the eye, collided with objects either moving or stationary?

If it is your right eye which is lost, have you experienced any difficulty with respect to :

(a) Traffic trying to overtake you.

\footnotetext{
*Copies of these questions can be obtained on application to Mr. Elmore BrewertoN, 73, Harley Street, W.1.
} 